Research paper

\title{
Identification of water stress conditions in olive trees through frequencies of trunk growth rate
}

\author{
M.J. Martín-Palomo ${ }^{\mathrm{a}, \mathrm{b}}$, M. Corell ${ }^{\mathrm{a}, \mathrm{b}}$, L. Andreu ${ }^{\mathrm{a}, \mathrm{b}}$, Y.E. López-Moreno ${ }^{\mathrm{a}}$, A. Galindo ${ }^{\mathrm{a}, \mathrm{b}}$, \\ A. Moriana ${ }^{a, b, *}$ \\ a Departamento de Agronomía, Universidad de Sevilla, ETSIA Crta. de Utrera Km 1, 41013 Seville, Spain \\ ${ }^{\mathrm{b}}$ Unidad asociada al CSIC de Uso sostenible del suelo y el agua en la agricultura (Universidad de Sevilla-IRNAS), Seville, Spain
}

\section{A R T I C L E I N F O}

Handling Editor: Dr. B.E. Clothier

\section{Keywords:}

Dendrometer

Trunk diameter fluctuations

Water relations

Water potential

Water status

\begin{abstract}
A B S T R A C T
Continuous monitoring of the tree water status will enhance irrigation performance, particularly when applying deficit schedules. The olive tree is a highly drought-resistant species and management of the water stress could increase water savings. Trunk diameter fluctuations can be displayed as daily curves representing the shrinkage and swelling, and can provide information about tree water status. In olive trees, trunk growth rate (TGR) is the most useful indicator, but the daily variability reduced the commercial applications. Recently, weekly frequencies of TGR values were associated to the water status in one seasonal experiment. The aim of this work is to study the seasonal pattern and the interannual variations of these parameters in order to integrate them in an irrigation scheduling tool. The experiment was performed during two consecutive seasons (2018 and 2019) in a superhigh density mature olive orchard at Carmona (Seville, Spain). Three different irrigation scheduling treatments were considered in a randomized complete block design. The control treatment was fully irrigated with 150-175\% crop evapotranspiration (ETc) in order to ensure an optimum water status. Regulated deficit irrigation-1 (RDI-1) was scheduled using only TGR data provided through the continuous measurements from a dendrometer. In this treatment, water stress conditions were controlled during the pit hardening period. RDI-2 was similar to RDI-1, but with a more severe water stress conditions during pit hardening and a maximum seasonal amount of water that limited rehydration. Water stress was greater during the 2019 season than the 2018 season, according to the midday stem water potential (SWP). Weekly frequencies of TGR values lower than $-0.3 \mathrm{~mm} \mathrm{day}^{-1}$ (Severe FR) and values between -0.1 and $0.3 \mathrm{~mm}$ day $^{-1}$ (Good FR) described the water status pattern in the three treatments for both seasons. Only under severe water stress conditions (SWP more negative than $-4 \mathrm{MPa}$ ) the values of these frequencies did not identify accurately the water status. However, the use of weekly frequencies of values greater than $0.3 \mathrm{~mm} \mathrm{day}^{-1}$ (Alert FR) and the pattern of these Severe FR and Good FR themselves identified such conditions. The use of these three weekly frequencies (Severe, Good and Alert (SGA) approach) are suggested for continuous deficit irrigation scheduling in olive trees.
\end{abstract}

\section{Introduction}

Irrigation management is a farm activity that many companies are trying to automate using different devices and approaches. Full irrigation conditions could be easily achieved with automatic weather stations and soil moisture sensors, which provide continuous estimation of the potential evapotranspiration (ETo) and the water applied. However, deficit irrigation schedules are more difficult to manage and, for most zones and species, they are becoming increasingly common. Olive trees (Olea europeae $\mathrm{L}$ ) are a good example of this type of water limitation. The irrigation needs for olive trees in a fully-irrigated superhigh-density orchard in the Guadalquivir valley was reported to be around $490 \mathrm{~mm}$ (Fernández et al., 2013) while the Spanish regulatory authorities for water use in this area (Confederación Hidrográfica del Guadalquivir, CHG) quantified the maximum availability as $250 \mathrm{~mm}$ (CHG, 2014). Olive is an extremely drought-resistant species (Diaz-Espejo et al., 2018) which is grown in rainfed conditions, but its profitability can be boosted in irrigated orchards (Moriana et al., 2003). The areas were this fruit tree is cultivated have arid and semi-arid climates with seasonal and scarce rainfall. Several authors reported that extremely severe water stress

\footnotetext{
* Corresponding author at: Departamento de Agronomía, Universidad de Sevilla, ETSIA Crta. de Utrera Km 1, 41013 Seville, Spain.

E-mail address: amoriana@us.es (A. Moriana).
} 
conditions during mid-summer had a low, or even negligible, impact on yield (Moriana et al., 2003; Fernández et al., 2013; Naor et al., 2013; Ahumada-Orellana et al., 2017). However, the high level of drought resistance is not the same throughout the season. A moderate water stress around full bloom (Moriana et al., 2003) or fruit set (Gómez del Campo, 2013; Gucci et al., 2019) decreased the current or the next season yield, and two important olive fruit features, size and amount of oil, could be equally affected if water stress is not controlled. Fruit growth was very sensitive to water stress, although the size could be recovered (Girón et al., 2015) or controlled when then midday stem water potential was more positive than $-2 \mathrm{MPa}$ (Martin-Palomo et al., 2020). The oil accumulation period has been considered a sensitive one (Lavee and Wodner, 1991), although some works suggested an increase oil rate under water stress conditions (Moriana et al., 2003; Lavee et al., 2007). Recently, Hueso et al. (2019) reported that a midday stem water potential more positive than $-2 \mathrm{MPa}$ did not affect oil accumulation. These data suggest that, even in a drought resistant species such as olive trees, an accurate deficit irrigation would be necessary to optimize water resources. New technologies are providing new ways to obtain a great amount of new data from an orchard. In recent years, continuous monitoring of traditional indicators (soil moisture, meteorological data) and the development of new sensors (e.g., leaf patch clamp pressure probe, Zimmermann et al., 2008) have become increasingly common. But deficit irrigation scheduling works based on these measurements are still very limited for olive orchards (e.g., Trunk diameter fluctuations).

Trunk diameter fluctuations are daily curves representing the shrinkage and swelling reported for the first time in the second half of the 20th century (Klepper et al., 1971). Although publications about this technique were initially very limited, Huguet et al. (1992) published an article suggesting the use of an irrigation scheduling device for peach trees ("Pepista") based on this approach. Since the 90's, the number of works using these daily curves increased and limitations on the usefulness of irrigation scheduling were reported. Goldhamer et al. (1999) noticed that the maximum daily shrinkage (MDS) was a water stress indicator for peach trees that provided information earlier than the midday stem water potential. Goldhamer and Fereres (2001) suggested the use of a MDS baseline for deficit irrigation and obtained very successful results in almond trees (Goldhamer and Fereres, 2004). For most fruit trees, MDS baselines were then reported, but with changes for different locations even when the same specie was being considered (Ortuño et al., 2010). However, for some particular fruit trees, the MDS was not a sensitive indicator of water stress (olive, Moriana and Fereres, 2002; prunes, Intrigliolo and Castell, 2006). The lack of MDS response to water stress in olive trees was related to the great dehydration capacity of this species (Moriana et al., 2000, 2010). As alternative, Moriana and Fereres (2002) suggested the trunk growth rate (TGR) as a sensitive indicator of water stress in olive trees. But the range of daily TGR variations are too wide in olive trees, so patterns and differences are not always clear (Girón et al., 2015; Agüero-Alcaras et al., 2016; Corell et al., 2019). Such variations were only partially related to changes in the evaporative demand (Girón et al., 2015; Corell et al., 2019). Corell et al. (2017) suggested that only values of TGR lower than $-0.1 \mathrm{~mm}$ day $^{-1}$ were a real indicator of water stress. However, irrigation scheduling based on these latter values was unsuccessful because under moderate water stress conditions or in a period of rehydration, very negative values of midday stem water potential were coincident with positive values of TGR (Corell et al., 2019). Corell et al. (2019) suggested that the relationship between TGR and water potential was not simple and, even in full irrigated trees, values of TGR could be changeable. In this work, the weekly frequency of different ranges of TGR changed with the severity of the water stress conditions, as such, it increased for the lowest negative values (lower than $-0.3 \mathrm{~mm}$ day $^{-1}$ ) and for the highest positive ones (more than $0.3 \mathrm{~mm} \mathrm{day}^{-1}$ ) but decreased for values between -0.1 and $0.3 \mathrm{~mm} \mathrm{day}^{-1}$ (Corell et al., 2019). These results were very novel but were based on data from just one season. Plant water status measurements are closely related to plant physiology and the environment. Thus, the main conclusion about TRG frequencies being related to midday water potential could be not real or, as there is not enough strong evidence to support the use of this indicator as a tool in RDI conditions. In addition, this latter work (Corell et al., 2019) presented the main ideas and suggest the use of frequencies in an RDI approach, but it did not comment on the implementation under field conditions.

The hypothesis of the current work is that the weekly frequency of TGR values lower than $-0.1 \mathrm{~mm}$ day $^{-1}$ could provide enough information to control deficit irrigation scheduling for olive trees. The aims of this work were (i) to validate if the relationship between TGR frequencies and water potential is similar for different seasons; and (ii) to assess the use of frequencies of values lower than $-0.1 \mathrm{~mm} \mathrm{day}^{-1}$ as an irrigation tool for RDI scheduling.

\section{Material and methods}

\subsection{Site and treatments description}

The experiment was performed during two consecutive seasons (2018 and 2019) in the commercial farm "El Morillo" in Carmona $\left(37.49^{\circ} \mathrm{N},-5.67^{\circ} \mathrm{W}\right.$, Seville, Spain). The olive (Olea europaea L) orchard was 12 years old at the beginning of the experiment. This is a superhigh density $(4 \times 1.5 \mathrm{~m})$ olive orchard cv Arbequina, irrigated daily through a single line with pressure compensated drips $\left(3.41 \mathrm{~h}^{-1}\right)$ separated $0.4 \mathrm{~m}$ each. Preliminary works in failed installation of $1 \mathrm{~m}$ soil moisture probes allowed estimating that the soil was very variable in depth, with plots ranging between $0.4 \mathrm{~m}$ to more than $1 \mathrm{~m}$ and with a large number of stones. The soil had a sandy-loam texture with a high $\mathrm{pH}$ level (8.4) and a high percentage of carbonates (greater than 25\%). The amount of $\mathrm{P}_{2} \mathrm{O}_{5}$ and $\mathrm{K}_{2} \mathrm{O}$ in the soil was adequate, and so was the percentage of organic matter (1.8\%).

The experimental design consisted of randomized complete blocks with 4 repetitions of 3 irrigation treatments. These treatments were based on phenology and water stress intensity. The irrigation season was divided into three different periods: from sprouting to the beginning of massive pit hardening, from pit hardening to the first week of September and from the first week of September to harvest. The beginning of pit hardening was estimated according to Rapoport et al. (2013). In brief, weekly longitudinal measurements of the fruit were determined from full bloom and the longitudinal growth showed to increase linearly until the maximum endocarp size was reached; then, it decreased sharply and pit hardening changes rapidly to increase the hardening rate (Rapoport et al., 2013). Recovery started the last week of August (day of the year, DOY, 242 in 2018 and DOY 237 in 2019).

The amount of water applied in the irrigation treatments was based on the following approach, for a daily irrigation scheduling:

- Control. No water stress conditions. The amount of water applied was estimated using the FAO approach for estimating the crop evapotranspiration (ETc) based on the crop coefficient (Kc) recommended for Córdoba (Spain) and a reduction coefficient of 0.8 . However, in previous works (Corell et al. 2019), this approach produced a slight decrease of the water potential in the mid-season. In order to ensure an optimum water status, the amount of water applied in the 2018 season was around $150 \%$ ETc and, in 2019, it was around $175 \%$ ETc.

- Regulated deficit irrigation-1 (RDI-1). Deficit irrigation during the pit hardening period using dendrometers as irrigation decision tool. The irrigation scheduling was based on trunk growth rate (TGR) according to Corell et al. (2017, 2019). In order to clearly identify the water status, irrigation was provided when the TGR was lower than $-0.1 \mathrm{~mm} \mathrm{day}{ }^{-1}$ or when the weekly frequency of these values was greater than $20 \%$. The irrigation rates changed according to the deviation for an optimum level and the phenological phase considered (Table 1). 
Table 1

Levels of water stress and applied water for the RDI-1 treatment throughout the experiment. The daily irrigation according to the phenological period and level of water stress is shown between brackets. The water applied values were selected according to the level of water, the trees measured, and the period considered. Period 1 (until the beginning of pit hardening), period 2 (pit hardening), period 3 (from end August/early September until harvest).

\begin{tabular}{|c|c|c|c|}
\hline & Period 1 & Period 2 & Period 3 \\
\hline $\begin{array}{c}\text { Level } \\
1\end{array}$ & $\begin{array}{l}\mathrm{TGR}<-0.1 \text { or } \\
\text { frequency }>20 \%(1.8 \\
\mathrm{mm})\end{array}$ & $\begin{array}{l}\mathrm{TGR}<-0.1(1 \\
\mathrm{mm})\end{array}$ & $\begin{array}{l}\mathrm{TGR}<-0.1 \text { or } \\
\text { frequency }>20 \%(1.8 \\
\mathrm{mm})\end{array}$ \\
\hline $\begin{array}{l}\text { Level } \\
2\end{array}$ & $\begin{array}{l}\text { TGR }<-0.2 \text { or } \mathrm{TGR}> \\
0.3(3.5 \mathrm{~mm})\end{array}$ & $\begin{array}{l}\mathrm{TGR}<-0.2(1.8 \\
\mathrm{mm})\end{array}$ & $\begin{array}{l}\text { TGR }<-0.2 \text { or } \mathrm{TGR}> \\
0.3(3.5 \mathrm{~mm})\end{array}$ \\
\hline Level & & $\mathrm{TGR}<-0.3$ or & \\
\hline 3 & & $\begin{array}{l}\text { TGR }>0.3(3.5 \\
\mathrm{mm})\end{array}$ & \\
\hline
\end{tabular}

- Regulated deficit irrigation-2 (RDI-2). This treatment had a maximum seasonal available amount of water $(170 \mathrm{~mm})$. In order to adjust irrigation scheduling to this maximum amount, the water stress was more severe during pit hardening than the in RDI-1 (Table 2). In addition, rehydration was stopped when the water applied reached maximum availability. However, during the 2019 season, the important scarcity of rainfall during spring and autumn forced to irrigate this treatment during rehydration with more than the maximum amount of water indicated. Afterwards, irrigation was provided from DOY 250 to maintain frequencies of TGR values below -0.1 between $40 \%$ and $60 \%$. These management actions increased the seasonal amount of water to $270 \mathrm{~mm}$.

\subsection{Measurements}

Climatic data were obtained from the web page of the "Sistema de información climática para el regadío" (Spanish Agriculture Ministry) and originated in the Andalusian weather station network, at the station "Villanueva de Rio y Minas", which is around $9.4 \mathrm{~km}$ away from the experimental plot (http://eportal.mapa.gob.es/websiar/SeleccionPa rametrosMap.aspx?dst=1). Potential evapotranpiration (ETo) and rain distribution were selected to characterize the locations. Average seasonal data were also obtained from these data for the period 2008-2017.

The amount of water applied was measured weekly with a water meter in each plot. Irrigation scheduling was performed daily using a remote programming device (Ciclón, C-146 v 3.53, Maher, Almeria, Spain).

The water relations were characterized weekly using soil moisture, midday stem water potential (SWP), gas exchange measurements and continuously with trunk diameter fluctuations. All these methodologies were used in each plot of the experiment. Soil moisture was measured at a 0.2 and $0.4 \mathrm{~m}$ depth with FDR sensors (Echo20 HS10, Decagon Device, USA) which were installed around $30 \mathrm{~cm}$ from an emitter (Fernández et al., 1991). SWP was measured in a leaf per plot, with the leaves covered for at least $2 \mathrm{~h}$ before, using a pressure chamber (PMS instruments, model 1000, Albany, USA). Two different methodologies

\section{Table 2}

Levels of water stress and applied water for the RDI-2 treatment throughout the experiment. The daily irrigation according to the phenological period and level of water stress is shown between brackets. The water applied values were selected according to the level of water, the trees measured, and the period considered. Period 1 (until the beginning of pit hardening), period 2 (pit hardening), period 3 (from end August/early September until harvest).

\begin{tabular}{clll}
\hline & Period 1 & Period 2 & Period 3 \\
\hline Level & TGR $<-0.1$ or frequency & TGR $<-0.2$ & TGR $<-0.1$ or frequency \\
1 & $>20 \%(1.8 \mathrm{~mm})$ & $(1 \mathrm{~mm})$ & $>20 \%(1.8 \mathrm{~mm})$ \\
Level & TGR $<-0.2$ or TGR $>0.3$ & TGR $<-0.3$ & TGR $<-0.2$ or TGR $>0.3$ \\
2 & $(3.5 \mathrm{~mm})$ & $(1.8 \mathrm{~mm})$ & $(3.5 \mathrm{~mm})$ \\
\hline
\end{tabular}

were used in gas exchange determinations because there were several damage problems. When an infrared gas analyzer was available (CI-340, CID BioScience, USA), this was the instrument used to measure net photosynthesis at midday in one fully expanded sunny leaf per plot. In some periods of the experiment, abaxial leaf conductance was measured with a porometer (SC-1, Decagon Device, USA) at midday in a fully expanded sunny leaf per plot.

Trunk diameter fluctuations were measured in one tree per plot using a band dendrometer ( $5 \mu \mathrm{m}$ accuracy, D6, UMS, Germany) attached to the main trunk. The band dendrometer is an extensiometric gauge that rests on a section of the trunk perimeter. The ends of the band were joined with Invar steel, an alloy of $\mathrm{Ni}$ and Fe with a thermal expansion coefficient close to zero (Katerji et al., 1994). The band and the Invar steel encircled the trunk. They have a Teflon net underneath to prevent friction with the bark surface. Each band dendrometer was plugged into a node (Widhoc smart solution SL, Spain) near the sensor. The nodes generated a stabilized power supply of $10 \mathrm{Vdc}$ to the band dendrometer and measurements were made every 15 min These nodes were integrated by two different parts. One being the measurement interface and other the processing, recording and communication system. Data from each sensor node were sent wirelessly to the cloud.

These devices provided a daily curve of shrinkage and swelling. Trunk growth rate (TGR) was calculated as the difference between two consecutive daily maximums (Goldhamer et al., 1999). Therefore, the TGR on day " $n$ " was the difference between the daily maximum value on day " $n+1$ " and " $n$ ". Daily TGRs are very changeable and the graphs generated are extremely confusing. In order to improve clarity, maximum diameter values were presented. In the resulting figure, the rate for each curve is the daily TGR. In this way, the statistical analysis can be easily presented in a more comprehensible way. Daily values of TGR were grouped in different ranges according to Corell et al. (2019) and the weekly frequency for each range was calculated. The selected ranges were: below $-0.3 \mathrm{~mm}^{\text {day }}{ }^{-1}$, between -0.3 and -0.2 , between -0.2 and -0.1 , between -0.1 and 0.3 , and greater than $0.3 \mathrm{~mm} \mathrm{day}^{-1}$. Therefore, 5 weekly frequencies of each range were obtained on each date. In order to increase clarity in the paper, frequencies below -0.3 $\mathrm{mm} \mathrm{day}{ }^{-1}$ were called "Severe FR", between -0.1 and $0.3 \mathrm{~mm}$ day $^{-1}$ were "Good FR" and greater than $0.3 \mathrm{~mm} \mathrm{day}^{-1}$ were "Alert FR". These are the main ones that will be used when showing the results and in the discussion section. The final approach derived from the use of this frequencies was named SGA approach.

\subsection{Statistical analysis}

Data were analysed by means of the one way-ANOVA using the Statistix program (SX, Analytical Software, USA) (8.0). The data normality was tested using a Shapiro-Wilk test. Differences in ANOVA were considered significant when p-level $<0.05$ in both tests. Calculations of the p-level were performed considering the F-test of variance equality (Homoscedasticity). When conditions of variance equality could not be obtained, a decrease in the degree of freedom and, therefore, a more restrictive $\mathrm{p}$-value was calculated. The number of samples measured is specified in the text and figures.

\section{Results}

Fig. 1 presents the climatic conditions throughout the two seasons of the experiment. Data showed that the rainfall and reference evapotranspiration (ETo) distribution were typical of a Mediterranean climate. Seasonal rainfall was greater than the average in 2018 (705 vs $538 \mathrm{~mm}$ ) but lower in 2019 (328 mm). There was a lengthy dry period from early spring to mid autumn in both seasons with very low, even null, rainfall. ETo data were greater than $6 \mathrm{~mm}^{\text {day }}{ }^{-1}$ from late spring until the end summer in both seasons. The 2018 season presented a shorter period of maximum ETo values than the 2019 one. Deficit irrigation was performed, in both seasons, during dry and very high 


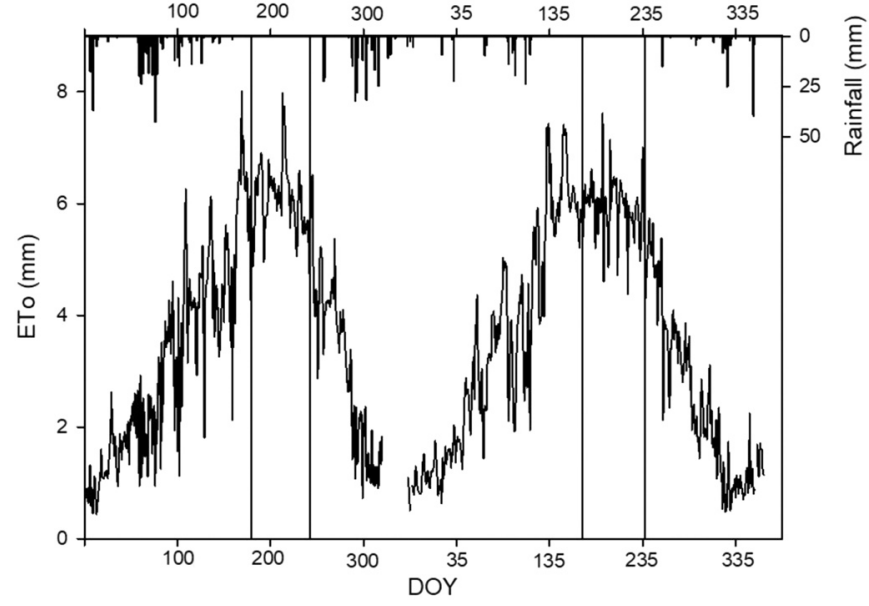

Fig. 1. Reference evapotranspiration (ETo, left) and rainfall (right) throughout the experiment in the 2018 and 2019 seasons. Vertical lines limit the periods of water stress each season. Source: Spanish Agrocimatic network, "Villanueva de rio y minas" station.

evaporative demand periods. The recovery of the trees also occurred under high evaporative demand conditions, generally greater than 4 $\mathrm{mm}$ day $^{-1}$, and almost absence of rain, at least at the beginning.

Fig. 2 presents the applied water patter generated by the climatic
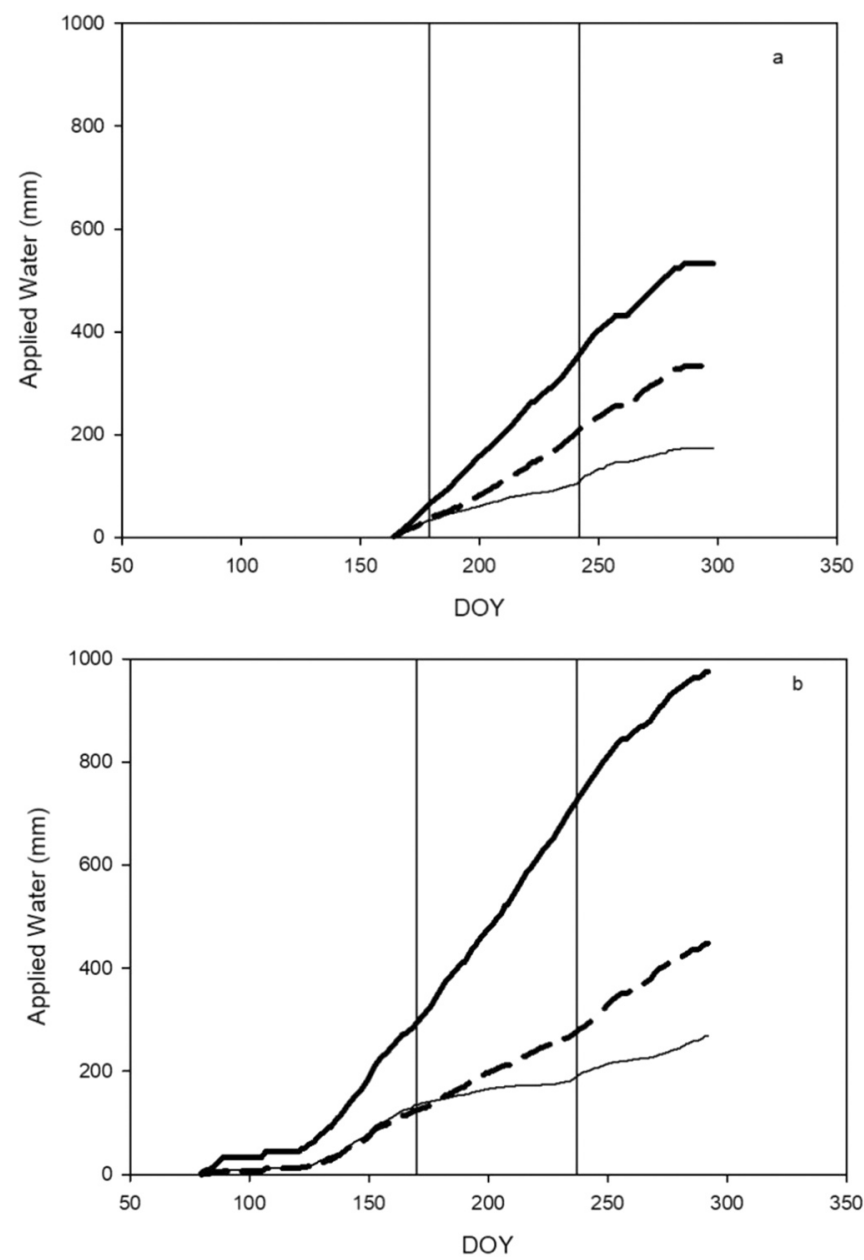

Fig. 2. Applied water during the two seasons of the experiment (a) 2018 and (b) 2019. Vertical lines limit the period of deficit irrigation. Solid bold line represents Control trees; Dash line represents RDI-1; Solid line represents RDI-2. conditions and irrigation scheduling. During 2018, the irrigation season started later (near DOY 150) than in 2019 (around DOY 75) because of the scarce rains in the 2019 season. The amount of water was greater in all treatments in the 2019 season than in the 2018 one. The main differences appeared between Control treatments, $50 \%$ greater, while in both RDIs, the increase was around $100 \mathrm{~mm}$. Control and RDI-1 were irrigated during the whole season, although the rate of water applied changed between treatments; it was lower in RDI-1 than in Control. The irrigation of RDI-2 sharply decreased during the deficit period, mainly in the 2019 season, and it increased after these dates.

Fig. 3 presents the soil moisture pattern at two different depths. No clear differences were found during the 2018 season between treatments. At $0.2 \mathrm{~m}$ depth (Fig. 3a), RDI-2 tended to produce lower values than Control and RDI-1, but with a greater variability. At $0.4 \mathrm{~m}$, the lowest values were obtained in RDI-1 during deficit treatments, although they were similar at the end to RDI-2 (Fig. 3b). During the recovery, the soil moisture increased at a depth of $0.2 \mathrm{~m}$ in RDI-1, but a clear recovery in all treatments and both depths was measured only after rains from DOY 300. During the 2019 season, the seasonal pattern was slightly different. At $0.2 \mathrm{~m}$ depth (Fig. 3c), RDI-2 showed lower values than Control and RDI-1, which were significant at the end of the deficit period and during the recovery. On the contrary, values in Control and RDI-1 were very similar. At a $0.4 \mathrm{~m}$ depth, there were no significant differences. Control and RDI-2 presented almost constant values during the deficit period, while, surprisingly, those for RDI-1 decreased.

Fig. 4 presents the seasonal pattern of midday stem water potential (SWP). The level and duration of the water stress was very different between seasons. In 2018, before the period of water deficit, all treatments were almost equal and near or even more positive than the baseline. In 2019, however, significant differences were found between RDIs and Control treatments during this period, and only Control data were above the baseline. These latter results were likely related to the considerable increase of irrigation in Control (Fig. 2). From the pit hardening period, the duration and water stress levels were very different between the 2018 and 2019 seasons. The lowest negative values of SWP were measured during pit hardening for both seasons. In the 2018 season, significant differences were found between RDI- 2 and Control, while RDI-1 showed intermediate values without statistical differences between both (Fig. 4a). Control SPW values decreased until $-2 \mathrm{MPa}$ from DOY 215-240. However, the minimum values were measured in RDI- 2 with $-4 \mathrm{MPa}$ at the end of this period (Fig. 4a). On the contrary, in the pit hardening period, the SPW in Control treatments during 2019 was more positive than the baseline and significantly different from RDI-2 (Fig. 4b). RDI-1 showed intermediate values without statistical differences between both (Fig. 4b). In this season, minimum values of SWP reached around $-5 \mathrm{MPa}$ in RDI- 2 and $-3 \mathrm{MPa}$ in RDI-1 (Fig. 4b), more negative than the ones of the previous season.

The level of water stress was reduced during rehydration, with a similar pattern in the two seasons. The SWP values increased rapidly until reaching similar conditions to Control (Fig. 4) in RDI-1 for both seasons. RDI-2 presented a partial recovery at the beginning of this period, but differences between seasons. The SWP values of RDI- 2 were similar to Control in 2018 (Fig. 4a), but significantly more negative in 2019 (Fig. 4b). For both seasons, SWP in RDI-2 decreased again until reaching moderate (in 2018, Fig. 4a) and severe (in the 2019 season, Fig. 4b) values. Only at the end of this period, when the rainfall period started, RDI-2 completely recovered.

The leaf gas exchange was less affected than the SWP (Fig. 5). During the 2018 season, RDI- 1 and Control data were very similar. Only significant differences between Control and RDI-2 were measured during the deficit period (Fig. 5a). During the recovery, there were no significant differences between treatments, but RDI-2 tended to lower values at the beginning, and, only from DOY 260 , these were similar to those from the rest of treatments (Fig. 5a). In 2019, there were differences between RDI-1 and Control, but they were not significant at any time (Fig. 5b and c). RDI-2 data tended to lower values most of the time, with significant 

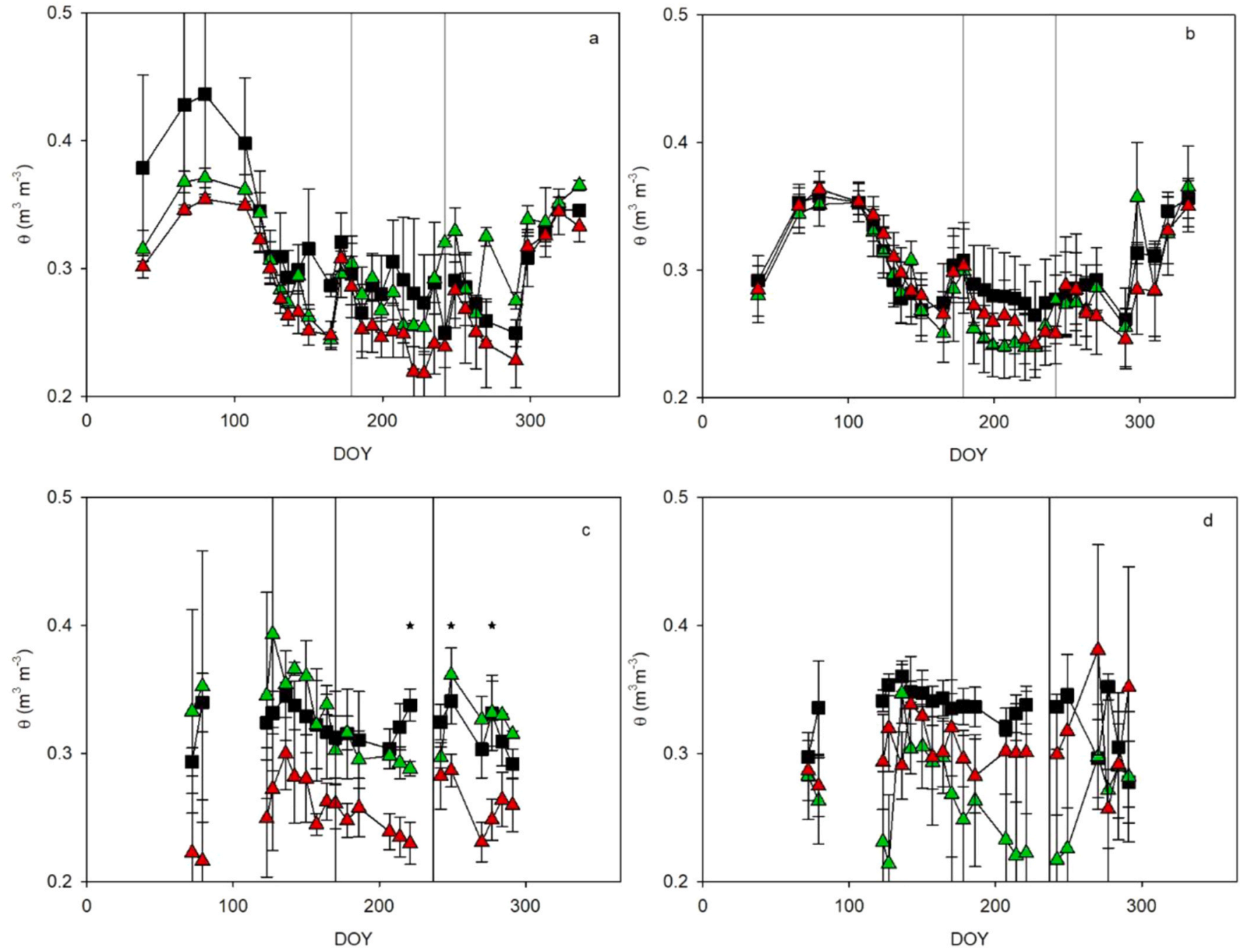

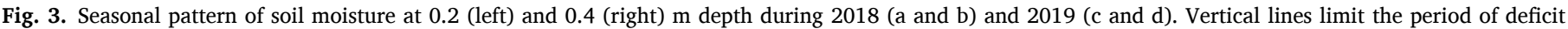

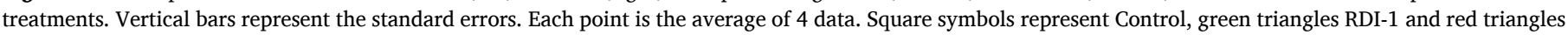

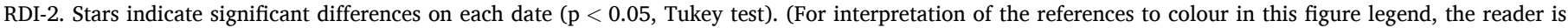
referred to the web version of this article).

differences on some dates only with Control trees. The recovery of this latter treatment, RDI-2, was not completed until the last date of the experiment (Fig. 5c).

Fig. 6 presents the pattern of TGR for both seasons. The continuous changes of these values and great increases and decreases caused these figures not to be clear. However, significant differences were found on different dates, more commonly during the deficit and the recovery periods. Fig. 7 is presented to clarify the description of TGR data and it shows the pattern of maximum trunk diameter (MXTD) and the significant differences of these TGR values, showing that the slopes of these figures are marked. The pattern of MXTD was similar during the 2018 and the 2019 seasons (Fig. 7). Before the deficit period in 2018 season, there were significant differences in trunk growth rate (TGR) between Control and RDI-2, all of them before irrigation started (around DOY 150) (Fig. 7a). These significant differences were also found in the 2019 season, but a few days before the deficit period, when Control started a continuous increase (Fig. 7b). During the deficit period in 2018 season, all treatments decreased the MXTD, but the TGR was significantly lower in RDI-2 than in the rest (Fig. 7a). On the other hand, there was no decrease of MXTD in Control trees during the deficit period of the 2019 season, but it appeared in the deficit treatments (Fig. 7b). Significant differences in TGR were measured between RDI-2 and Control in this period during 2019. In the recovery period of 2018, Control and RDI-1 presented a similar pattern, with a greater recovery in the latter. On the contrary, RDI-2 presented cycles of increase and decrease of MXTD with significant differences in the TGR of Control. During 2019, MXTD increased in Control until around DOY 250 when the values became steady. RDI-1 presented a sharp increase, but also stopped at around this date. RDI-2, as in the previous season, presented cycles of increase and decrease with significant differences in TGR with Control.

Fig. 8 presents the weekly frequency of TRG values lower than $-0.1 \mathrm{~mm} \mathrm{day}{ }^{-1}$ ( "Bad FR"). Before the deficit period in the 2018 season, there were no clear differences between treatments (Fig. 8a). Bad FR changed during this period from 0 to more than $60 \%$ in all treatments. A similar pattern was observed in the 2019 season until DOY 127, when Control decreased, reaching values lower than $20 \%$ consistently and RDIs were significantly greater (Fig. 8b). During the deficit period, differences between Control and the rest of treatments increased in both seasons. In 2018, the Bad FR in Control treatments oscillated between almost zero and $40 \%$, but RDIs increased to $60 \%$, and significant differences with Control were measured (Fig. 8a). In 2019, these differences were clearer between Control and RDIs. In this period and for most dates, Control was significantly lower than RDIs, and even significant differences were measured between RDI-2 and RDI-1. Control was steadily lower than $20 \%$, while RDI- 2 oscillated between $40 \%$ and $60 \%$ and RDI- 1 was more stable around $40 \%$ (Fig. 8 b). During recovery in 

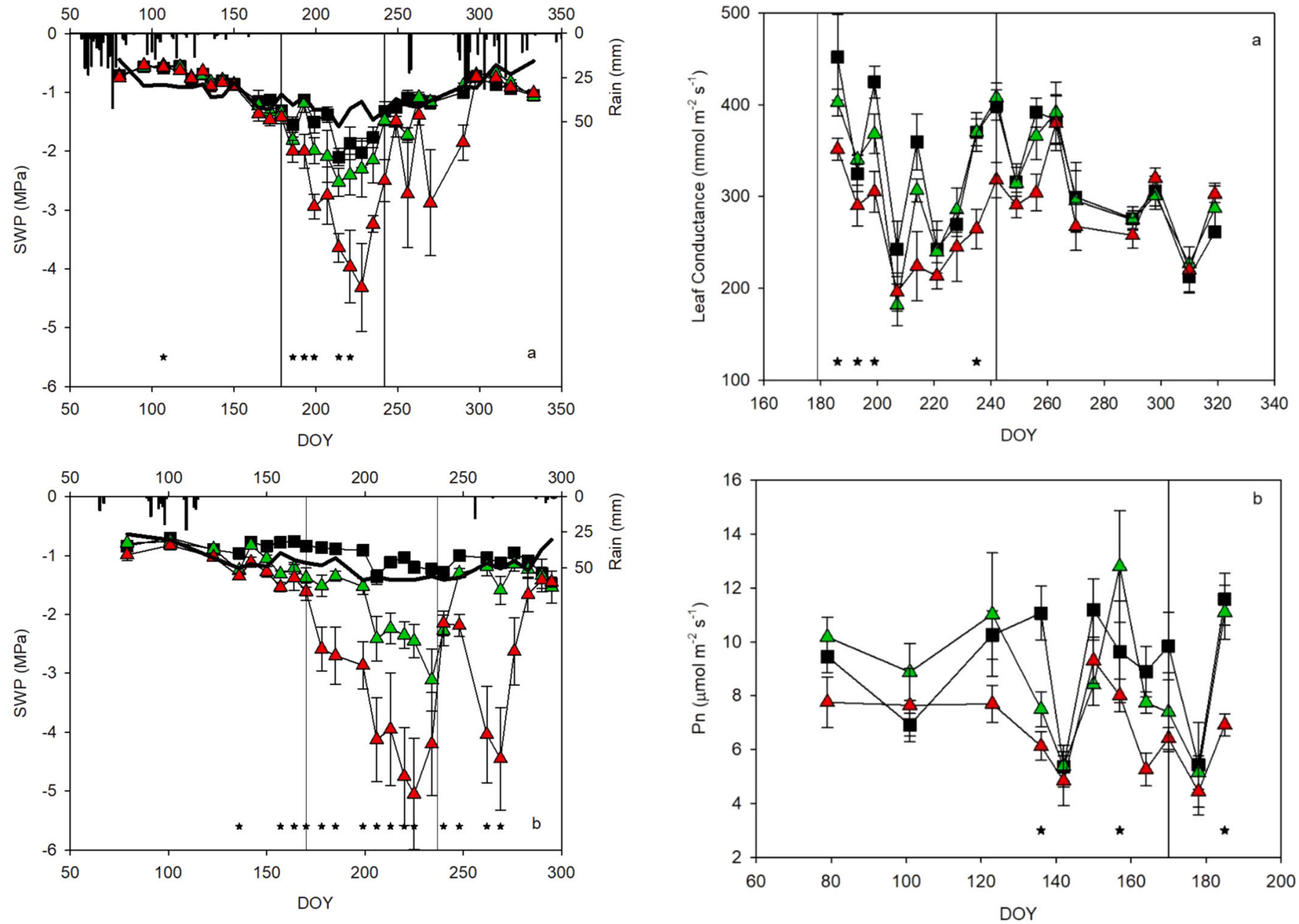

Fig. 4. Seasonal pattern of midday stem water potential (left axis) and rainfall (right axis) during the 2018 (a) and 2019 (b) seasons. Vertical lines limit the deficit period. Vertical bars represent the standard error. Bold solid lines represent the midday stem water potential expected according to the Corell et al. (2017) baseline. Each symbol is the average of 4 data. Square, Control treatments; green triangles, RDI-1; red triangles, RDI-2. Stars indicate the dates when significant differences were found ( $\mathrm{p}<0.05$, Tukey test). (For interpretation of the references to colour in this figure legend, the reader is referred to the web version of this article).

2018, there were significant differences between Control and RDI-2, but not with RDI-1, which showed intermediate values (Fig. 8a). From DOY 300 , all treatments presented almost equal values. In 2019, such differences were clearer than in the previous season, with significantly greater values in RDI- 2 and very similar from DOY 252 between Control and RDI-1 (Fig. 8b). RDI-2 values increased from less than $20 \%$ at the beginning of the recovery to more than $60 \%$ on DOY 257 , then they decreased sharply until DOY 275.

Fig. 9 presents the pattern of weekly frequency for different interval of TGR vs four levels of water stress according to the SWP data. All the TGR intervals are presented for both seasons and for all water stress levels. Frequency of TGR values lower than $-0.3 \mathrm{~mm} \mathrm{day}^{-1}$ (so called "Severe FR") increased in both seasons with the level of water stress, from frequencies lower than $10 \%$ when SWP values were more positive than $-1.4 \mathrm{MPa}$ to greater than $40 \%$ (in 2018) or around $30 \%$ (in 2019), when the SWP values were more negative than $-4 \mathrm{MPa}$. These Severe FR were significantly different between different water stress levels, and only in the 2019 season, the last two levels were not. These variations were lower in the frequencies of intermediate values (between -0.3 and -0.2 and between -0.2 and $-0.1 \mathrm{~mm} \mathrm{day}^{-1}$ ), when no significant differences or small increases were measured in any season. The greatest

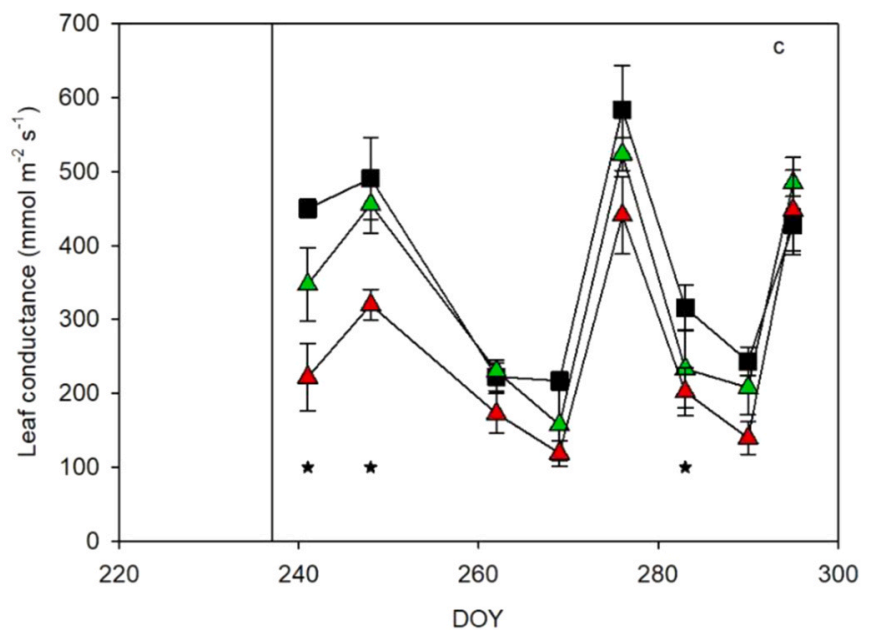

Fig. 5. Pattern of leaf gas exchange during the experiment. (a) Midday leaf conductance during the 2018 season. (b) Midday leaf Photosynthesis during the first part of the 2019 season. (c) Midday leaf conductance during the recovery period of the 2019 season. Vertical lines indicate the deficit period. Vertical bars represent standard error. Each symbol is the average of 4 data. Black square, Control, green triangle, RDI-1, and red triangle, RDI-2. Asteriks indicated significant differences on that date (Tukey test $p<0.05$ ). (For interpretation of the references to colour in this figure legend, the reader is referred to the web version of this article). 

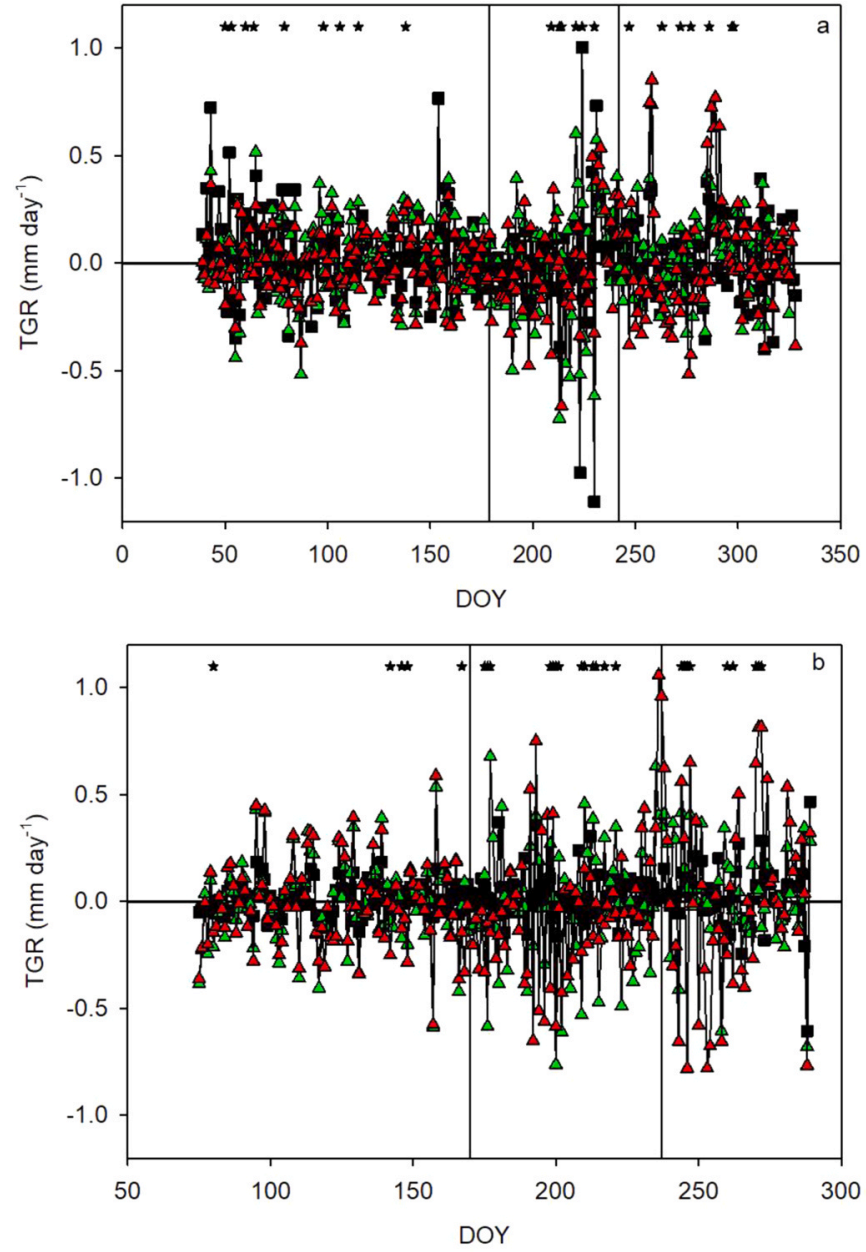

Fig. 6. Pattern of trunk growth rate (TGR) throughout the 2018 (a) and 2019 (b) experimental seasons. Each symbol is the average of 4 data. Vertical lines limit the deficit period. Black square, Control treatment; green triangles, RDI-1; red triangles, RDI-2. Asterisks indicat significant differences in the TRG on that date (Tukey test, $\mathrm{p}<0.05$ ). (For interpretation of the references to colour in this figure legend, the reader is referred to the web version of this article).

changes occurred in the frequency of values between $-0.1-0.3 \mathrm{~mm} \mathrm{day}^{-1}$ (so called "Good FR"). The frequency of these values decreased sharply from near $70 \%$ in the less severe water stress levels to 30\% (in 2018) or 40\% (in 2019). As in Severe FR, such values were significantly different for different stress levels, although no significant variations were found between the two more negative intervals of SWP. Lastly, the frequency of values greater than $0.3 \mathrm{~mm} \mathrm{day}^{-1}$ (so called "Alert FR") increased from the less severe interval of water stress with values lower than $10 \%$ to values around $30 \%$ in the interval -4 to $-2.5 \mathrm{MPa}$, but with a sharply and significant decrease in both seasons when the SWP values were lower than $-4 \mathrm{MPa}$.

Fig. 10 presents the pattern of frequencies more sensitive to the water stress level during the 2018 and 2019 seasons (Severe, Good and Alert FR). Before the deficit period, most of the data show no significant differences in the 2018 season (Fig. 10a-c). All frequencies were consistently similar between treatments. Severe FR were commonly lower than $10 \%$, similar to Alert FR. Only Good FR kept changing, although most of the time remained above $60 \%$. The pattern for this period during the 2019 season was different (Fig. 10d-f). There were no significant differences in Severe FR, but Control presented the minimum values (zero) most of the time, while RDIs were around 10\% (Fig. 10d). Good FR were again very changeable, but significant differences were found from DOY 128 between Control and RDIs (Fig. 10e). Alert FR were
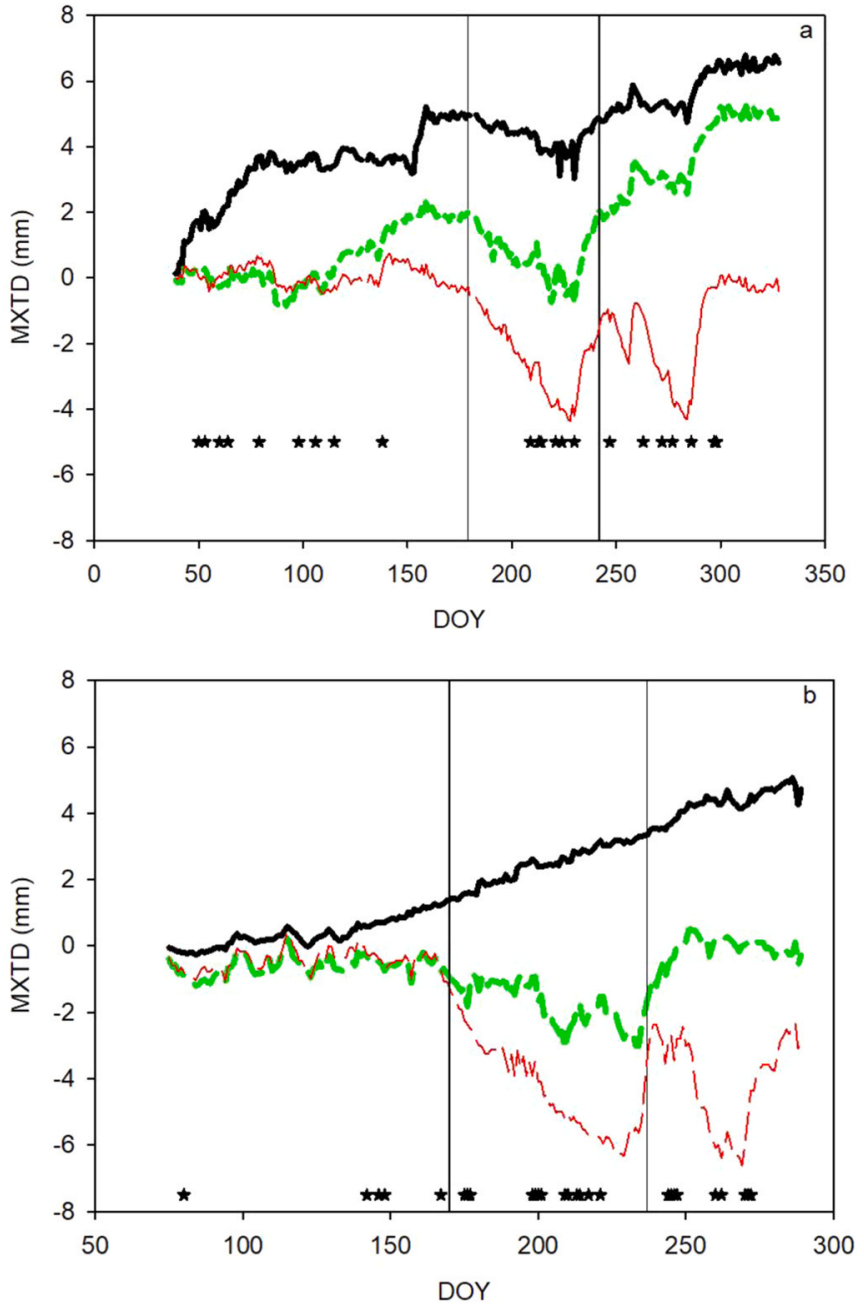

Fig. 7. Maximum trunk diameter (MXTD) throughout the experiment during 2018 (a) and 2019 (b). Vertical lines limit the deficit period. Data are the average of four measurements. Bold solid lines, Control; bold green dash lines, RDI-1; red dash line RDI-2. Asterisks indicat significant differences in the TRG on that date (Tukey test, $\mathrm{p}<0.05$ ). (For interpretation of the references to colour in this figure legend, the reader is referred to the web version of this article).

near zero in Control treatments for most of this period, while RDIs showed cycles of frequency increase and decrease, sometimes reaching values greater than $30 \%$ and significantly different from Control. (Fig. 10f).

The greatest differences were found in the deficit period for both seasons. Severe FR of RDIs were significantly greater than Control most of the time in the 2018 and 2019 seasons (Fig. 10a and d). At the end of this period in the 2019 season, DOY 206, these frequencies sharply decreased in RDI-2, reaching values lower than $10 \%$ and not significantly different from Control (Fig. 10d). Good FR were significantly greater in Control than in RDIs in both seasons for most of the deficit period (Fig. 10b and e). Only in 2018, Control presented a sharply decrease of Good FR from DOY 223 until DOY 234. At the end of deficit period in 2019, Good FR increased in RDI-2, reaching values near to $60 \%$, while in RDI- 1 they decreased to values around $20 \%$. Alert FR were also significantly greater in RDIs than in Control during most of the deficit period in both seasons, with maximum values greater than $50 \%$ vs zero in Control. At the end of this period in 2019, from DOY 207, the values for RDI-2 sharply decreased and reached levels similar to Control, while RDI-1 reached their maximum values.

During the recovery period, Severe FR were still significantly 

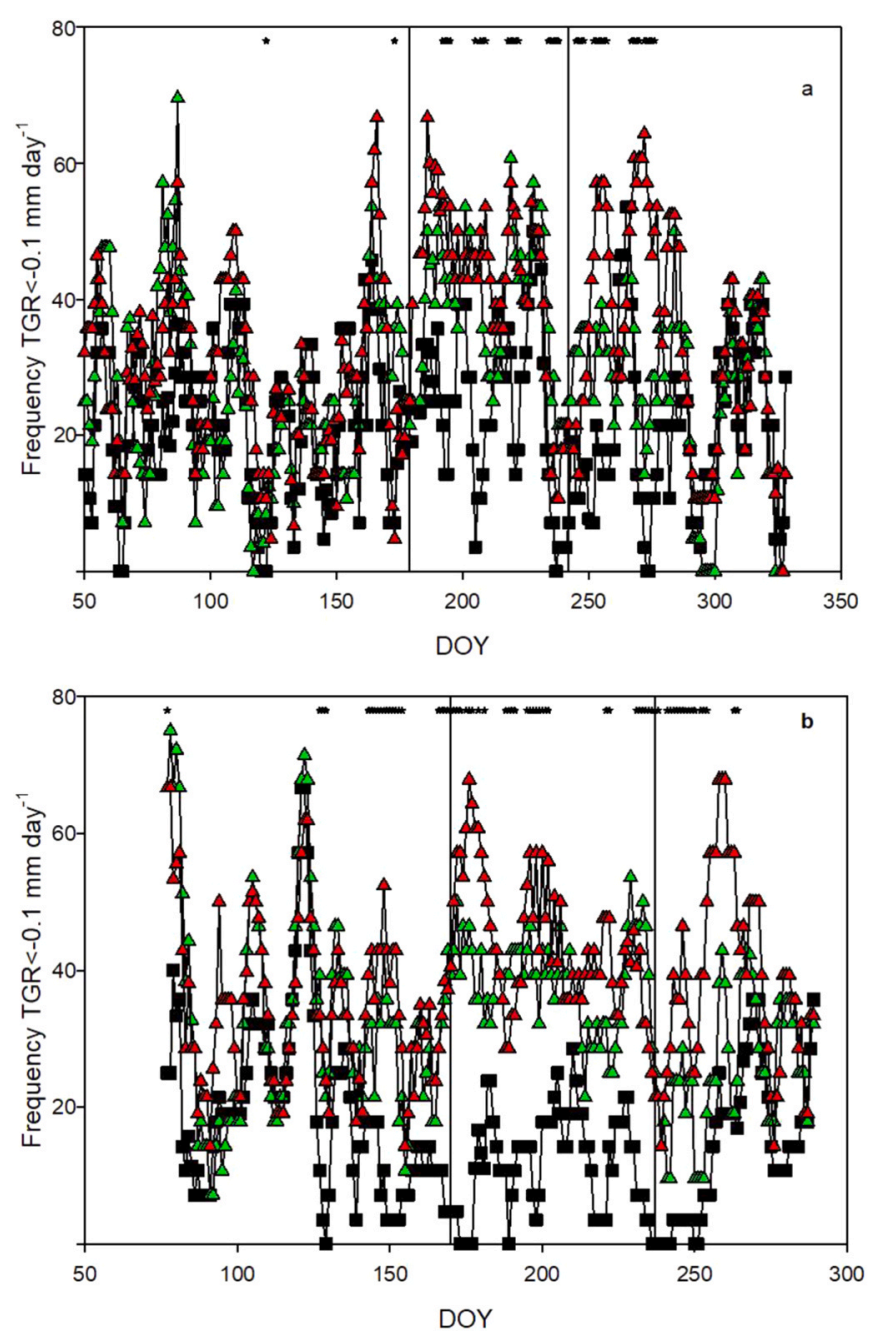

Fig. 8. Weekly frequency of trunk growth rate (TGR) values lower than $-0.1 \mathrm{~mm}$ day-1 throughout the experiment during the 2018 (a) and 2019 (b) seasons. Vertical lines limit the deficit period. Each symbol is the average of 4 data. Black square, Control treatment; green triangles, RDI-1; red triangles, RDI2. Asterisks indicat dates when significant differences were measured $(\mathrm{p}<0.05$, Tukey test). (For interpretation of the references to colour in this figure legend, the reader is referred to the web version of this article).

different between Control and RDI-2 in both seasons, while the differences between RDI-1 and Control decreased gradually (Fig. 10c-f). The same pattern was measured in Good FR for both seasons, and values were significantly lower in RDIs than Control at the beginning. RDI-1 presented a clear recovery during the rehydration phase, that was delayed in RDI- 2 until the end of the experiment. Alert FR was clearly different during 2019 between Control and RDIs, and with RDI-2 from DOY 270. However, these differences were lower during the 2018 season and only significant for a narrow period of time.

\section{Discussion}

The usefulness of the MXTD curve and the TGR values was limited (Figs. 6 and 7) and only the weekly frequency of TGR data presented a clear pattern associated to the water status (Figs. 8-10). Traditionally, significant differences in TGR were associated with water stress conditions in olive trees (Moriana et al., 2013; Girón et al., 2015; Aguero-Alcaras et al., 2016) and other trees (such as Populus tomentosa, Li et al., 2020), but the differences between different water status was lower than when frequencies are used (Corell et al., 2019). Data presented for both seasons (Fig. 9) and in a previous work (Corell et al.,
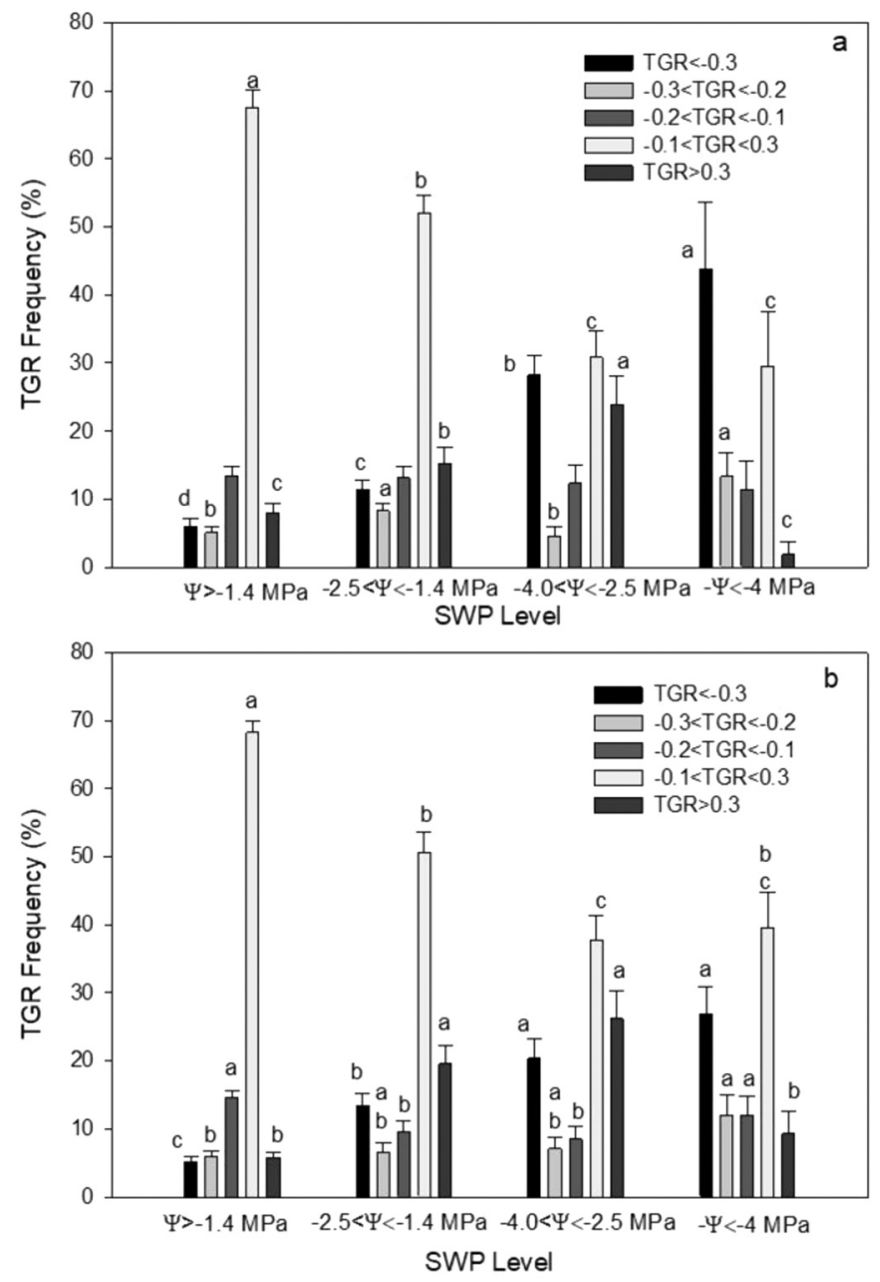

Fig. 9. Pattern of trunk growth rate (TGR) frequency of several intervals at 4 different intervals of midday stem water potential (SWP) during the 2018 (a) and 2019 (b) seasons. Each bar is the average of different amount of data depending on the SWP considered. Lines represent the standard error. Different letters in the same interval of TGR indicate significant differences $(p<0.05$ Tukey test).

2019) showed that the pattern of frequencies in relation to SWP was similar in three different seasons. Therefore, this tool could be conservative enough to be used in irrigation scheduling. These data suggest that the effect of evaporative demand on these indicators was limited and no baseline was needed for data interpretation. No significant relationship was found between VPD and any Control frequencies (data shown in Supplementary Material). The evaporative demand has been frequently one of the main problems hindering the use of trunk dimeter fluctuations indicators in irrigation scheduling. After Goldhamer and Fereres (2001) suggested using a baseline in the management of maximum daily shrinkage (MDS) as an irrigation tool, many equations have been reported even for the same fruit tree (Ortuño et al., 2010). Such equation variability caused some works to suggest estimations of a baseline at the beginning of each irrigation season (Egea et al., 2009). The drought sensitivity of these frequencies was close to the one presented in SWP and gas exchange, ensuring an early and accurate water stress detection. Moriana and Fereres (2002) reported that TGR showed a greater sensitivity than SWP and gas exchange for young olive trees, as for other fruit trees such as peaches with MDS (Goldhamer et al., 1999).

The main challenge is to design an approach to differentiate the levels of water stress. The use of a single frequency of TGR values lower than $-0.1 \mathrm{~mm}^{\text {day }}{ }^{-1}$ means that, even in full irrigated conditions, this frequency was high and changes in water status were not clear presented 

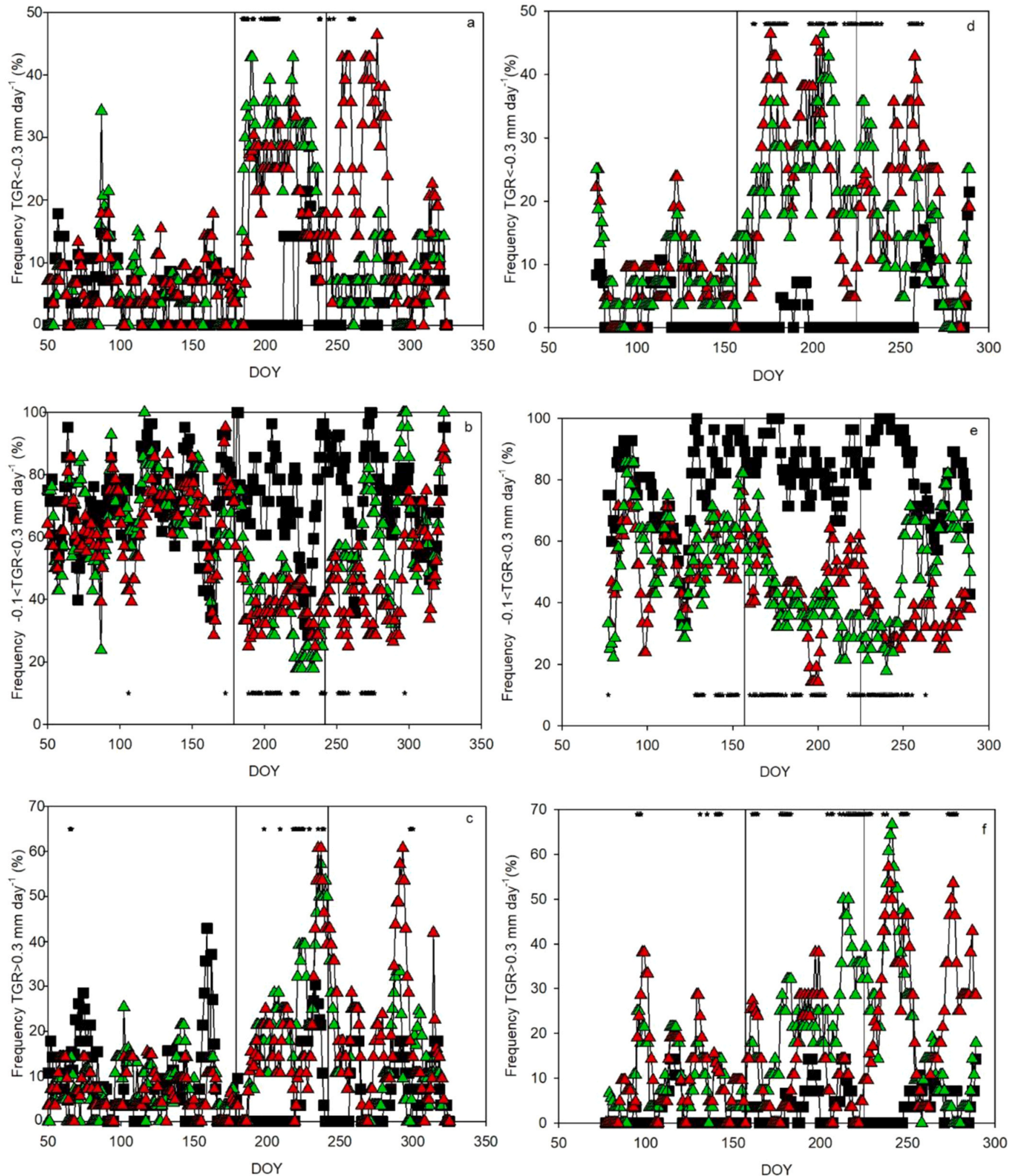

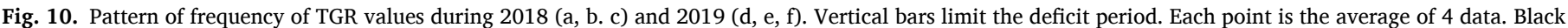

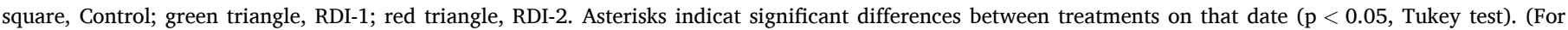
interpretation of the references to colour in this figure legend, the reader is referred to the web version of this article).

(Fig. 8). Therefore, under conditions of mild water stress, the differentiation with other levels would be difficult (Fig. 8a vs Fig. 4a). When TGR data was separated in the selected ranges and frequencies considered (Severe, Good and Alert approach), the identification of the water stress level improved (Fig. 10). According to the literature, SWP values greater than $-1.4 \mathrm{MPa}$ are considered full irrigated conditions (-1.4 MPa, Moriana et al., 2012; -1.0 MPa, Gómez-del-Campo, 2013). These range of SWP values are coincident with very low percentages 
$(<10 \%)$ of Severe and Alert FRs. Good FR could be used to differentiate between mild (around 60\%) and no water stress (greater than 80\%). In this interval of SWP, important changes were found in Good FR and moderate increases in Severe FR, with relative low variations in SWP (Fig. 10a-c; DOY 150-165, 256-263 in 2018 or Fig. 10d-f; DOY 199-206, 283-290 in 2019). Such changes in Good FR could be associated with variations in the trunk water content (Simonneau et al., 1993). Under these conditions, the trunk probably did not lose water when considering the net daily balance, and the changes could be associated to a reversible flux of water from the bark to xylem (Brough et al., 1986). Within this range of SWP, changes of "in situ" turgor water potential curves have been reported (Fernández et al., 2011; Marino et al., 2016). Diaz-Espejo et al. (2018) suggested that, in this moderate range of water stress $(-1.1$ to $-1.5 \mathrm{MPa})$, the SWP was maintained, while turgor pressure fluctuated.

The increase of the water stress changed the TGR frequency values. Moderate water stress conditions characterized with SWP values between -1.4 to more positive than $-3 \mathrm{MPa}$ would decrease Good FR down to values around $40 \%$, while Severe FR progressively increased. Maximum Severe FR were estimated using SWP around the most negative values (Figs. 4 and 9). Alert FR were also increased but not all the time. Corell et al. (2019) reported that important increases of TGR (in the range of the Alert FR) were related to irrigation or rainfall events. Therefore, Alert FR would occur in response to irrigation or rainfall events but, otherwise, values would be zero or very low. All these frequencies suggest a net loss of water in the trunk and could be associated with an increase in xylem embolism. At the beginning of this range in olive trees, between -1.7 and $-2 \mathrm{MPa}$, the daily curves for the turgor pressure presented an inverse shape (Fernández et al., 2011; Marino et al., 2016) and xylem embolism increased (Diaz-Espejo et al., 2018). Moreover, leaf conductance in olive trees could be unaffected at the beginning, but the gas exchange would be significantly reduced when SWP was close to -3 MPa (Moriana et al., 2002; Moriana and Fereres, 2002). Such restriction in leaf conductance was not affected at the frequencies considered.

The most severe water stress conditions changed the pattern of these frequencies. On average (Fig. 9), the increase of water stress to SWP lower than -4 MPa caused the continuous decrease of Good FR over the previous level to stop. This worsening of the water stress reduced the increase of Severe FR in 2019 (Fig. 9b). Moreover, when the daily frequency values are considered (Fig. 10) in the most severe period (from DOY 206-234 in the 2019 season), fast changes are observed in both. Severe FR changed continuously from maximum to minimum values (RDI-2 from DOY 206-234; Fig. 10d). The opposite occurred in Good FR under the same conditions (RDI-2 from DOY 206-234; Fig. 10e). This latter increase was not as big as under full irrigated conditions, but it was similar to a moderate water stress (around $40-50 \%$ in Good FR). Then, at the end of a severe and long period of water stress, these two frequencies could present data which suggest a water stress smaller than the real one. This process would be a false rehydration. However, Alert FR slightly increased in this period (Fig. 10f) and could identify such conditions. This level of water stress probably presented no changes in the water content of the trunk. Under very negative SWP values, the trunk dimeter fluctuation curve was reported with a very low MDS and no response to evaporative demand (Moriana et al., 2000), which is a response similar to that of leaf conductance, almost constant for a wide range of VPD (Moriana et al., 2002).

\section{Conclusions}

A wide range of water status levels in olive trees was described using data from three different frequencies of the TGR interval (Severe, Good and Alert (SGA) approach). This description was similar for two different seasons. Only frequencies for values lower than $-0.1 \mathrm{~mm}$ day ${ }^{-1}$ were not useful for RDI scheduling. Severe and Good FR presented great changes with low variations of SWP in mild and moderate water stress conditions. Severe FR increased with the decrease of SWP, while Good FR presented important increases and decreases based on changes in SWP. Alert FR was also useful, but only when irrigation events occurred. In very severe water stress conditions, Severe and Good FR changed patterns, and "false positives" were obtained for the water status, with a decrease and an increase of values respectively. Such changes in absence of irrigation or rain could be informative enough to identify these conditions, because a continuous monitoring is expected. In addition, irrigation of trees in such conditions will cause a clear and sharp increase of Alert FR, which would allow identifying very severe water stress conditions.

\section{Declaration of Competing Interest}

The authors declare that they have no known competing financial interests or personal relationships that could have appeared to influence the work reported in this paper.

\section{Acknowledgement}

This research was supported by the Agencia Española de Investigación (AEI) and the Fondo Europeo de Desarrollo (FEDER) project AGL2016-75794-C4-4-R. Authors thank to Finca El Morillo for their helpful assistant during the experiment, specially to Mr Javier León.

\section{Appendix A. Supporting information}

Supplementary data associated with this article can be found in the online version at doi:10.1016/j.agwat.2020.106735.

\section{References}

Agüero-Alcaras, L.M., Rousseaux, M.C., Searles, P.S., 2016. Responses of several soil and plant indicators to postharvest regulated deficit irrigation in olive trees and their potential for irrigation scheduling. Agric. Water Manag. 171, 10-20.

Ahumada-Orellana, L.E., Ortega-Farias, S., Searles, P.S., Retamanes, J.B., 2017. Yield and water productivity responses to irrigation cut-off strategies after fruit set using stem water potential thresholds in a super-high density olive orchard. Front. Plant Sci. 8 https://doi.org/10.3389/fpls.2017.01280.

Brough, D.W., Jones, H.G., Grace, J., 1986. Diurnal changes in water content of the stems of apple trees, as influenced by irrigation. Plant Cell Environ. 9, 1-7.

Confederación hidrográfica del Guadalquivir (CHG), 2014. Propuesta de proyecto de revisión del Plan hidrológico de la demarcación hidrográfica del Guadalquivir Anejo $\mathrm{n}^{\circ} 32014$ Descripción de usos, demandas y presiones,.Anejo $\mathrm{n}^{\circ} 3$ 〈https://www.ch guadalquivir.es/descargas/PlanHidrologico2015-2021/Guadalquivir/04-ANEJO\% 20N3.\%20DESCRIPCION\%20DE\%20USOS,\%20DEMANDAS\%20Y\%20PRESIONES. pdf).

Corell, M., Martín-Palomo, M.J., Pérez-López, D., Centeno, A., Girón, I., Moreno, F. Torrecillas, A., Moriana, A., 2017. Approach for using trunk growth rate (TGR) in the irrigation scheduling of table olive orchards. Agric. Water Manag. 192, 12-20.

Corell, M., Martín-Palomo, M.J., Girón, I., Andreu, L., Trigo, E., López-Moreno, Y.E., Torrecillas, A., Centeno, A., Pérez-López, D., Moriana, A., 2019. Approach using trunk growth rate data to identify water stress conditions in olive trees. Agric. Water Manag. 222, 12-20.

Diaz-Espejo, A., Fernández, J.E., Torres-Ruiz-, J.M., Rodriguez-Dominguez, C.M., PerezMartin, A., Hernandez-Santana, V., 2018. The olive tree under water stress: fitting the pieces of response mechanisms in the crop performance puzzle. In: GarciaTejero, I., Martin-Zuago, V.H. (Eds.), Water Scarcity and Sustainable Agriculture in Semiarid Environment. Tools, Strategies and Challenges for Woody Crops. Academic Press, Elsevier, London.

Egea, G., Pagán, E., Baille, A., Domingo, R., Nortes, P.A., Pérez-Pastor, A., 2009. Usefulness of establishing trunk diameter based reference lines for irrigation schedulingin almond trees. Irrig. Sci. 27, 431-441.

Fernández, J.E., Moreno, F., Cabrera, F., Arrue, J.L., Martín-Aranda, J., 1991. Drip irrigation, soil characteristics and the root distribution and root activity of olive trees. Plant Soil 133, 239-251.

Fernández, J.E., Rodriguez-Dominguez, C.M., Pérez-Martín, A., Zimmermann, U., Rüger, S., Martín-Palomo, M.J., Torres-Ruiz, J.M., Cuevas, M.V., Sann, C., Ehrenberger, W., Diaz-Espejo, A., 2011. Online-monitoring of tree water stress in a hedgerow olive orchard using the leaf patch clamp pressure probe. Agric. Water Manag. 100, 25-35.

Fernández, J.E., Perez-Martin, A., Torres-Ruiz, J.M., Cuevas, M.V., RodriguezDominguez, C.M., Elsayed-Farag, S., Morales-Sillero, A., Garcia, J.M., HernandezSantana, V., Diaz-Espejo, A., 2013. A regulated deficit irrigation strategy for hedgerow olive orchards with high plant density. Plant Soil 372, 279-295. 
Girón, I.F., Corell, M., Martín-Palomo, M.J., Galindo, A., Torrecillas, A., Moreno, F., Moriana, A., 2015. Feasibility of trunk diameter fluctuations in the scheduling of regulated deficit irrigation for table olive trees without references trees. Agric. Water Manag. 161, 114-126.

Goldhamer, D.A., Fereres, E., 2001. Irrigation scheduling protocols using continuously recorded trunk diameter measurements. Irrig. Sci. 20, 115-125.

Goldhamer, D.A., Fereres, E., 2004. Irrigation scheduling of almond trees with trunk diameter sensors. Irrig. Sci. 23, 11-19.

Goldhamer, D.A., Fereres, E., Mata, M., Girona, J., Cohen, M., 1999. Sensitivity of continuous and discrete plant and soil water status monitoring in peach tress subjected to deficit irrigation. J. Am. Soc. Hortic. Sci. 124, 437-444.

Gómez del Campo, M., 2013. Summer deficit irrigation in a hedgerow olive orchard cv Arbequina: relationship between soil and tree water status, and growth and yield component. Span. J. Agric. Res. 11, 547-557.

Gucci, R., Caruso, G., Gennai, C., Esposto, S., Urbani, S., Servili, M., 2019. Fruit growth, yield and oil quality changes induced by deficit irrigation at different stages of olive fruit development. Agric. Water Manag. 212, 88-98.

Hueso, A., Trentacoste, E.R., Junquera, P., Gomez-Miguel, V., Gomez del Campo, M., 2019. Differences in stem water potential during oil synthesis determine fruit characteristics and production but not vegetative growth or return bloom in an olive hedgerow orchard (cv. Arbequina). Agric. Water Manag. 223, 105589 https://doi. org/10.1016/j.agwat.2019.04.006.

Huguet, J.G., Li, S.H., Lorendeau, J.Y., Pelloux, G., 1992. Specific micromorphometric reactions of fruit trees to water stress and irrigation scheduling automation. J. Hortic. Sci. Biotechnol. 67, 631-640.

Intrigliolo, D., Castell, J.R., 2006. Performance of various water stress indicators for prediction of fruit size response to deficit irrigation in plum. Agric. Water Manag. 83, 173-180.

Katerji, N., Tardieu, F., Bethenod, O., Quetin, P., 1994. Behavior of Maize stem diameter during drying cycles: comparison of two methods for detecting water stress. Crop Sci. 34, 165-169.

Klepper, B., Browing, V.D., Taylor, H.M., 1971. Stem diameter in relation to plant water status. Plant Physiol. 48, 683-685.

Lavee, S., Wodner, M., 1991. Factors affecting the nature of oil accumulation in fruit of olive (Olea europea L.) cultivars. J. Hortic. Sci. Biotechnol. 66, 583-591.

Lavee, S., Hanoch, E., Wodner, M., Abramowitch, H., 2007. The effect of predetermined deficit irrigation on the performance of cv Muhasan olives (Olea europaea L) in the eastern coastal plain of Israel. Sci. Hortic. 112, 156-163.

Li, D., Fernández, J.E., Li, X., Xi, B., Jia, L., Hernandez-Santana, V., 2020. Tree growth patterns and diagnosis of water status based on trunk diameter fluctuations in fastgrowing Populus tomentosa plantations. Agric. Water Manag. 241, 106348 https:// doi.org/10.1016/j.agwat.2020.106348.
Marino, G., Pernice, F., Marra, F.P., Caruso, T., 2016. Validation of an online system for the cntinuous monitoring of tree water status for sustainable irrigation managements in olive (Olea europaea L). Agric. Water Manag. 177, 298-307.

Martin-Palomo, M.J., Corell, M., Girón, I., Andreu, L., Galindo, A., Centeno, A., PérezLópez, D., Moriana, A., 2020. Absence of yield reduction after controlled water stress during prehaverst period in table olivetrees. Agronomy 10, 258 doi:103390/ agronomy10020258.

Moriana, A., Fereres, E., 2002. Plant indicators for scheduling irrigation for young olive trees. Irrig. Sci. 21, 83-90.

Moriana, A., Fereres, E., Orgaz, F., Castro, J., Humanes, M.D., Pastor, M., 2000. The relations between trunk diameter fluctuations and tree water status in olive tree (Olea europea L). Acta Hortic. 537, 293-297.

Moriana, A., Villalobos, F.J., Fereres, E., 2002. Stomatal and photosynthetic responses of olive (Olea europaea L.) leaves to water deficits. Plant Cell Environ. 25, 395-405.

Moriana, A., Orgaz, F., Fereres, E., Pastor, M., 2003. Yield responses of a mature olive orchard to water deficits. J. Am. Soc. Hortic. Sci. 128, 425-431.

Moriana, A., Girón, I., Martín-Palomo, M.J., Conejero, W., Ortuño, M.F., Torrecillas, A., Moreno, F., 2010. New approach for olive trees irrigation schedulings using trunk diameter sensors. Agric. Water Manag. 97, 1822-1828.

Moriana, A., Pérez-López, D., Prieto, M.H., Ramírez-Santa-Pau, M., Pérez-Rodriguez, J. M., 2012. Midday stem water potential as a useful tool for estimating irrigation requirements in olive trees. Agric. Water Manag. 112, 43-54.

Moriana, A., Corell, M., Girón, I.F., Conejero, W., Morales, D., Torrecillas, A., Moreno, F., 2013. Regulated deficit irrigation based on threshold values of trunk diameter fluctuation indicators in table olive trees. Sci. Hortic. 164, 102-111.

Naor, A., Schneider, D., Ben-Gal, A., Zipori, I., Dag, A., Kerem, Z., Birger, R., Peres, M., Gal, Y., 2013. The effects of crop load and irrigation rates in the oil accumulation stage on yield and water relations of Koroneki olives. Irrig. Sci. 31, 781-791.

Ortuño, M.F., Conejero, W., Moreno, F., Moriana, A., Intrigliolo, D.S., Biel, C., Mellisho, C.D., Pérez-Pastor, A., Domingo, R., Ruiz-Sánchez, M.C., Casadesus, J., Bonany, J., Torrecillas, A., 2010. Could trunk diameter sensors be used in woody crops for irrigation scheduling? A review of current knowledge and future perspectives. Agric. Water Manag. 97, 1-11.

Rapoport, H.F., Pérez-López, D., Hammami, S.B.M., Aguera, J., Moriana, A., 2013. Fruit pit hardening: physical measurements during olive growth. Ann. Appl. Biol. 163, 200-208.

Simonneau, T., Habib, R., Goutouly, J.P., Huguet, J.G., 1993. Diurnal changes in stem diameter depend upon variations in water content: direct evidence in peach trees. J. Exp. Bot. 44, 615-621.

Zimmermann, D., Reuss, R., Weshoff, M., Geßner, P., Bauer, W., Bamberg, E., Bentrup, F. W., Zimmerman, U., 2008. A novel, non-invasive, online monitoring, versatile and easy plant-based probe for measuring leaf water status. J. Exp. Bot. 59, 3157-3167. 